\section{DISCUSSION AND CORRESPONDENCE THE TEMPLE HILL (ORANGE COUNTY, N. Y.) MASTODON}

THE 101st separate record of mastodon remains in the state of New York and the 31st record for Orange County, have been made by the recent discovery of an almost complete skeleton on the muck lands near Temple Hill about three quarters of a mile northwest of Vail's Gate Junction. The discovery is of exceptional interest. Next to the Warren Mastodon which stands in the American Museum of Natural History, the Temple Hill skeleton follows in order of completeness, all bones being present except a part of the cranium and a few of the ribs. While the skeleton appears to be somewhat larger than that of the Cohoes Mastodon in the New York State Museum, it is evident that the bones are those of a young animal, as the epiphyses are free and there is a full set of four intermediate molars in addition to the complete permanent molars, making in all 12 teeth in both jaws. The animal was found lying on its side with a quantity of triturated plant remains, apparently tamarack, lying between the ribs, evidently the creature's last meal. The skeleton was discovered about the 10th of June and was immediately acquired for the State Museum through the generosity of an appreciative friend.

The Mastodon was the most conspicuous member the mammal fauna of New York ever had, and it is perhaps of special interest to again note, with this occasion, the great abundance of these creatures in the state during the time of the recession of the postglacial waters, especially over the swampy highlands before the land had settled down to its present altitude. After all the disturbances to which the soil of New York and its contents have been subjected, the wasting by the weather and the various other agencies attacking and destroying the integrity of such remains, the abundance of the recorded discoveries of mastodon bones in the state can only be interpreted as indicating the fact that in their heyday these animals were as abundant here as the buffalo were on the plains
75 years ago; and it is also a fact worthy of consideration by those giving attention to soil changes, that of all these 101 recorded skeletons but two or three have been preserved in anything approaching entirety.

New York State MUSEUM,

Sherman C. Bishop July 6,1921

\section{A MORE PHENOMENAL SHOOT}

The July 1, number of Science records a "phenomenal shoot" which grew near Raleigh, N. C. This shoot grew from the stump of a beheaded tree of Paulownia tomentosa in one season to the length of 19 feet 5 inches; had twenty internodes, and was 7.75 inches in circumference at the base. This shoot is thought by Mr. Wells to be " a record for the tree type of woody plant in the temperate zone."

During the past season the writer kept track of a shoot which grew from stump of a beheaded tree of Paulownia tomentosa. This shoot grew during the season of 1920 to a length of 21 feet 6 inches, it has twenty-four internodes and is ten inches in circumference at the base. One of the leaves, measured in the latter part of July, was 38 inches in largest dimension. This shoot grew in clay loam soil residual from granite on property adjoining the campus of the University of North Carolina, Chapel Hill, N. C. The shoot is on exibition in the Geological Museum of the University.

\section{Chaper Hirl, N. C.}

W. F. Prouty

\section{A PHYTOPHTHORA PARASITIC ON PEONY}

EarLy in May the writers received from Mrs. George Ray, of Erie, Pa., some blighted peonies. Since the cause of the trouble was not at once apparent, cultures were attempted from the diseased portions. These yielded at once a pure growth of Phytophthora. As the writers are not aware of any previous report of a Phytophthora as a parasite on this host, a brief description of the disease and the causal organism is here made a matter of record, pending further investigation. 